\title{
EDUCACIÓN: UN ACERCAMIENTO PRAXEOLÓGICO
}

\author{
"Las convicciones son esperonzo" (Bentold Brech)
}

\author{
Por: Carlos Germán Juliao Vargas*
}

\section{Resumen}

En este trabajo se hace una opción interpretativa de la educación, fundamentada en la emergencia del pensamiento crítico, considerándola como una disciplina que valora especialmente la dimensión subjetiva del ser humano, que asume una forma cualitativa de realizar investigación en educación, que acepta que la verdad se ve afectada por la visión del mundo de los actores del proceso educativo, y que se interesa por problemáticas sociales que tienen relación directa con la educación, como la pobreza o la equidad. Y sobre todo, con esta visión, se admite la posibilidad emancipatoria de la acción educativa. Todo esto condicionado a una posición epistemológica que asume la complementariedad entre conocimiento y aplicación, entre teoría y práctica; planteamiento que no es otra cosa que la praxeología. Por eso, desde dichos planteamientos teóricos, se concluye presentando el trabajo praxeológico en educación en tanto reflexión práctica sobre los principios de la acción educativa y de sus técnicas, que busca, igualmente, los principios generales y la metodología adecuada para un quehacer educativo eficaz y pertinente.

\section{Palabras Claves}

Educación, Praxeología, Teoría pedagógica, Praxis educativa, Educación social, Acción humana, Compromiso social, Profesional reflexivo.

\section{Perfil}

Carlos Germán Juliao V. es Filósofo y Teólogo, con Maestría en Estudios Sociales, Políticos y Económicos de la Universidad Católica de París, también realizó la Maestría en Dirección Universitaria de la Universidad de los Andes.

\begin{abstract}
Critical thinking as an emergent discipline, concerned with educational issues and related topics such as poverty and equity, values the subjective dimension of human beings, uses qualitative research in education taking into account the fact that the truth is affected by the world vision of those who take part in the educational process. The emancipatory dimension of education. From an epistemological standpoint, knowledge and its application are complementary as theory and practice is. This sis called praxeology. Education may become a practical reflection upon the principles that rule it as well as its practices.
\end{abstract}

\section{Keywords}

Education, Praxeoloy Pedagogical theory, Social Education, Human Action, Social commitment, Reflective professional.

\section{Artículo:}

Recibido, 28 de julio de 2006; aprobado, 28 de Noviembre de 2006 


\section{EDUCACIÓN: UN ACERCAMIENTO PRAXEOLÓGICO.}

La educación, como hecho cultural, se puede mirar de múltiples formas: como suceso histórico, como proceso de formación humana, como los modos de vivir y de pensar que deben ser afinados, como el acervo de bienes culturales a transmitir o recrear, etcétera; de ahí que la principal característica de la educación sea la apertura a distintas corrientes de pensamiento. Sea como sea, el hecho educativo no se puede justificar por sí mismo, sino por su significado sociocultural. En este trabajo se hace una opción interpretativa de la educación que se fundamenta en la emergencia del pensamiento crítico, con los aportes de grupos como la Escuela de Frankfurt o de pedagogos como Freire, entre otros; opción que concibe la pedagogía como una disciplina que valora especialmente la dimensión subjetiva del ser humano, que asume una forma cualitativa de realizar investigación en educación, que acepta que la noción de verdad se ve afectada por la visión del mundo de los actores del proceso educativo, y que se interesa por problemáticas sociales que se considera tienen relación directa con la educación, como la pobreza o la equidad. Y sobre todo, con esta visión, se admite la posibilidad emancipatoria de la acción educativa.

Pero todo esto está condicionado a un planteamiento epistemológico que asume la complementariedad entre conocimiento y aplicación, entre teoría y práctica; planteamiento que no es otra cosa que la praxeología, que señala que el diálogo entre el saber y la acción, en un proceso de reflexividad, le proporciona al profesional los instrumentos prácticos para determinar si la acción que realiza es eficaz y cuáles serían las otras acciones de mejora a emprender. La praxeología ayuda a captar la riqueza teórica escondida en las acciones educativas y, por ende, a incrementar el acervo de planteamientos pedagógicos; así como a mejorar, programáticamente, las mismas acciones educativas, apoyándose en dicho acervo pedagógico. $Y$ de paso, facilita que el profesional de la educación se convierta en un profesional reflexivo'.

\section{A. LA EDUCACIÓN COMO TEORIÁ Y PRÁCTICA.}

Se parte de un supuesto elemental: únicamente la pertenencia a un grupo y a una cultura permite que se desarrolle la educabilidad del ser humano. La educación ${ }^{2}$ participa así de la acción comunicadora ${ }^{3}$ de la sociedad y lo ideal es que, gracias a ella, "cada individuo genere su propia concepción del mundo, seleccione el rol que asumirá y construya sus niveles de aspiración en función de los cuales orientará su actividad y compromisos históricos" (García Carrasco, 1984: 42). De algún modo dicha acción "enculturizadora" tiene que ver con la formación de la ciudadanía":

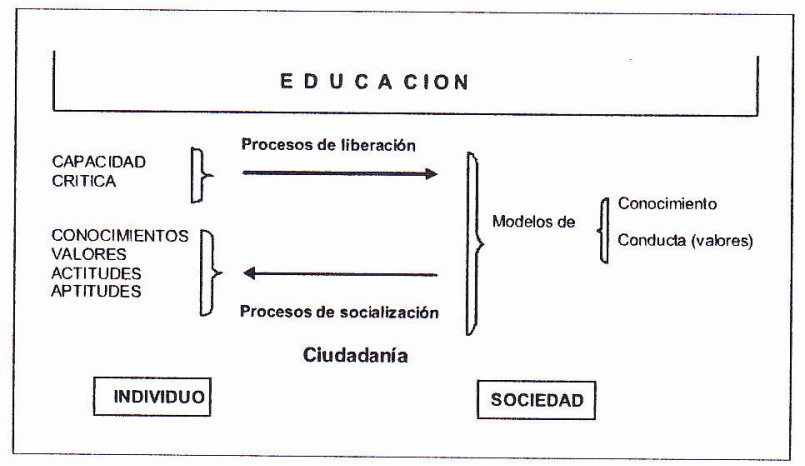

La educación es una acción social orientada hacia unas finalidades en la que se realiza una influencia, deliberada e intencional, sobre los sujetos para ayudarles a realizar unos proyectos individuales y sociales y cumplir las metas propuestas (Bernabeu, 1997). Hay que entenderla, pues, como una actividad intencional y una necesidad sociocultural, como lo

\footnotetext{
1. Aquí se asume una visión general, optimista y constructivista, que consiste en ver el proceso de reflexividad como un proceso de generación de conocimiento cuyo movimiento normal, con ideas generales, pretende recuperar la acción social. Se acentúa más la conducta que la naturaleza, se utiliza la estrategia y el conocimiento adquiere un rol fundamental.

2. El concepto "educación" comienza a usarse con una ambigüedad y polisemia natural desde el comienzo: junto a la promoción del individuo (educere:"conducir hacia, hacer salir") está su "dotación" socializadora para que actúe con los demás (educare: criar, alimentar, instruir).

3. Se sigue aquíla idea de Dewey de que la sociedad/comunidad implica la "comunicación" de algo que es "común" (la cultura) y de que "toda comunicación (y, por tanto, toda vida social auténtica) es educativa (...) toda organización social...es educadora para quienes participan en ella" (2001, cap.1, parág. 2)

4. La figura siguiente se toma, con algunos ajustes, de Fullat (1983: 16).
} 
plantearon Durkheim y Dewey. La educación es el proceso de integración cultural y personal del ser humano a una comunidad.

La educación, entonces, no es una suma de intereses y acciones individuales, sino una tarea social, un quehacer social a lo largo de la vida que permite que todo ser humano, desde su nacimiento hasta su muerte, se vaya formando como individuo que vive en grupo y en sociedad, para desarrollarse como persona e intervenir en la vida de la comunidad de la que hace parte ${ }^{5}$. No es otra cosa que lo que los griegos denominaron paideia $^{6}$, esa suma de relaciones, influjos, enseñanzas, aprendizajes, etcétera, que vivían los ciudadanos en el ámbito de la polis: no había un tiempo para la educación y otro para la vida; toda la vida era educación; la ciudad era el educador por excelencia. No se diferenciaba entre una educación formal (escolar) y otra educación social.

A partir de la llustración y de las revueltas burguesas, los gobiernos fueron generando los sistemas nacionales de instrucción y formación que reclamaba la creciente complejidad socioeconómica de los Estados y la necesidad de transmitir la ideología imperante: se fue construyendo un sistema educativo formal, aislado en la misma sociedad en la que surgía, centrado exclusivamente en la escuela ${ }^{7}$. Durante el siglo XIX la escuela convirtió el saber en saber escolar, lo que "le significó tener una comprensión específica acerca de la enseñanza y de la pedagogía $y$, además, desarrollar procedimientos particulares de transmisión de ese saber completamente diferentes a los procedimientos de la construcción del saber" (Mejía-Awad, 2003: 51), es decir, asumió una tarea específica: ser la transmisora del saber sistematizado, acumulado a lo largo de la historia (Martínez, 1990), creando para ello una didáctica que terminó confundiéndose con la pedagogía, al apartar los procesos pedagógicos del resto de procesos socializadores.

Cuestionada la escuela, desde mediados del siglo XIX, se amplió a más clases sociales, buscando su legitimación en una mayor cobertura, en el interés por la comunidad en la que se insertaba y abriéndose a la naturaleza y a la vida; pero lo hizo desde el pensamiento escolar. Paulatinamente se ha querido ampliar la influencia de la educación a aquellos escenarios que quedan "fuera de la escuela", pero siempre pensando en aulas y pedagogía escolar. La educación era escolar o no era. Este aislamiento de la escuela limitó la pedagogía al proceso de enseñanza y a las interacciones que se producen en el contexto de la institución escolar. Los efectos de todo esto son graves: primero, la interacción social, sobrentendida en la educación, se desdibujó y se redujo a una mera relación escolar; y segundo, los procesos educativos, que se daban en diversos niveles, olvidaron su relación con lo social como totalidad.

Sin embargo, en las últimas décadas del siglo $X X$, surge otra visión, desde diversas perspectivas de pensamiento y acción crítica; inicialmente a esa otra educación, propia de comunidades locales, asociaciones, ONG's, etcétera, se la llamó, desdeñosamente, educación "no formal" o "informal". Pero, ante el hecho innegable de que "la comunicación media una negociación entre vida cotidiana, cultura ilustrada y procesos masivos construidos como imaginario colectivo, en donde la televisión, la gallada de jóvenes y la cultura de masas van también a la escuela, afectando sus procedimientos y reconstruyendo de otra manera las relaciones sociales escolares"

5. Conviene distinguir entre educación (o "proceso educativo") como realidad (hechos) que tendría que ver con las ciencias, tanto naturales como sociales, y educación como valor (deber ser), que tendría que ver con la filosofía, la antropología, la moral, la estética y la política. Difícilmente puede excluirse del concepto educación la referencia al valor y a la ética: se educa en función de un sistema de valores.

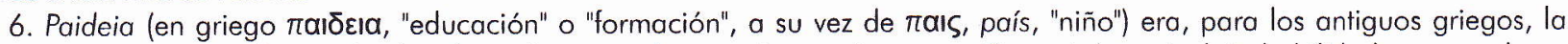
educación que confería a los hombres de un carácter realmente humano. Como tal, no incluía habilidades manuales o erudición en temas específicos, que eran considerados técnicos e indignos de un ciudadano; por el contrario, la paideia se concentraba en la formación que haría del individuo una persona apta para ejercer sus deberes cívicos y sociales.

7. El concepto proviene del griego pasando por el latín; en latín es schola, en griego es: $\sigma$ Xoגń ("eskolé"); paradójicamente el significado era el del momento de recreo o diversión; luego se dio un deslizamiento de significado en la mayoría de los idiomas indoeuropeos modernos; el significado actual más frecuente es el de un "establecimiento público" en donde se transmiten enseñanzas: es el "santuario" del sistema escolar formal, creación de la Revolución Francesa (plan Condorcet) que le dio el 
(Mejía-Awad, 2003: 52), hoy aceptamos que hay mucha más educación afuera que dentro del sistema escolar y que la escuela debió estar siempre en el ámbito de la "educación a lo largo de la vida" para no perder su significado ni su legitimación.

Es necesaria, por tanto, una nueva lectura que libere la pedagogía de la escuela y asuma el reto de plantear unas pedagogías acordes con la idea de que, en tanto acción social a lo largo de la vida, la educación hay que comprenderla como educación permanente, "como la condición de un desarrollo armonioso y continuo de la persona" (Delors, 1996: 91) y, en tanto tal, no se limita a lo enseñable ni al aprendizaje de conocimientos, sino que se centra en lo formativo y educable ${ }^{8}$. Se trata de una reconceptualización de la educación que retoma y revaloriza la dimensión ética y sociocultural del proceso educativo, la comprensión de sí mismo y de su ambiente para ser miembro de una familia, para ser un ciudadano responsable y también productor de contenidos culturales y solidario y colaborador con los otros. Obviamente todo esto encierra una educación fundamental (básica) de calidad, adquirible ciertamente en las instituciones escolares, pero pensada en una perspectiva flexible, variada y asequible en diversos momentos y espacios.

Que la educación al margen de la escuela sea hoy más significativa es un indicio que comienza a invertir lo establecido: en efecto, en el espacio de la paideia, de la ciudad educativa, de la sociedad educadora, de la educación a lo largo de la vida, ingresan todos con iguales derechos y dignidad; nadie esta fuera del sistema, se trata de la comunidad, de la vida en sociedad. Este es el ámbito de la educación social; allí estuvo siempre. Resumiendo estos planteamientos, se puede concluir:

- Que la educación debe ser la construcción paulatina de la persona para el desarrollo de sí misma y para la participación en la vida comunitaria y social; que su misión es ayudar a comprender el mundo y a los demás, para que así la persona se comprenda a sí misma; que deberá enseñar a ser y a convivir.

- Que la educación es una dimensión de la vida misma de los sujetos y de las comunidades; es educación "a lo largo de la vida" y, por eso, no se da ni exclusiva ni primariamente en una determinada fase de la vida.

- Por eso, la educación en y a lo largo de la vida cotidiana es el lugar y el tiempo de toda educación, en el que la educación escolar debe insertarse como una instancia más de la misma, potenciando todos sus objetivos y no limitándose a la transmisión y memorización de contenidos cognitivos.

- Que toda educación es o debe ser social. No existe auténtica educación individual si no se forma al individuo para vivir y convivir en la comunidad y viceversa.

- La educación social, en sentido estricto, que es sobre la cual se va a reflexionar en este texto, tanto como teoría (pedagogía social) y como praxis (práctica educativa, fenómeno o estructura con instituciones, proyectos, currículos, etcétera) debe insertarse asimismo en el ámbito de la "educación a lo largo de la vida cotidiana", marco en el que siempre estuvo, como otra instancia más, si bien, en su caso, lo haga frecuentemente en lugares y tiempos diferentes a los de la educación escolar.

Es claro, entonces, que la educación, como acción transformadora a lo largo de la vida (praxis

papel de entregar el saber sistematizado y de lograr la homogeneización social para franquear la desigualdad de nacimiento en la que se basaba el antiguo régimen.

8. Los conceptos de educabilidad y enseñabilidad están en mutua relación. La enseñabilidad se supedita a la relación que se establezca entre la naturaleza de los saberes y los contextos y ambientes de la enseñanza. La educabilidad depende de las condiciones de los estudiantes, de sus "competencias", y del modo como los contenidos culturales puedan adecuarse, a través de un proceso de recontextualización, a dichas competencias. 
no restringida a la actividad instrumental o techne) que desencadena algo imprevisto en las personas, grupos y sociedades, es imprescindible para la vida en el mundo del nosotros, para la vida social, si se orienta a la autonomía, es decir, a que cada uno sea capaz de conducirse a sí mismo, en medio de los otros, superando el conflicto natural de las relaciones sociales. Como proceso formativo del sujeto social no puede caer en las actuales ideologías de poiesis, de fabricación en serie o de rendimiento productivo, pero tampoco reducirse a acciones que sólo importan a los sujetos como individuos. La educación siempre podrá aportar a este mundo descentrado y confundido si es capaz de repensarse, sin dejarse llevar por los paradigmas positivistas o tecnológicos del momento que tienden a reducirla al aprendizaje individual, al adiestramiento, 0 , peor aún, al control de las conductas. $Y$ es que la educación logra su auténtica utilidad, por paradójico que parezca, cuando se distancia de lo estrictamente pragmático y asume que "solo sirve para vivir en el mundo $y$, a ser posible, vivir mejor. $Y$ esto no se fabrica, no se mide, no se anticipa $y_{\text {, siendo un }}$ poco osados, tampoco se enseña, aunque puede aprenderse" (GARCIAMOLINA, J., 2003: 24).

Ahora bien, la educación así concebida implica la relación entre teoría, práctica e investigación en un proceso crítico-reflexivo y praxeológico, que no favorece a ninguno de los tres componentes considerándolo como esencial. $\mathrm{O}$, dicho de otro modo, la educación y, más específicamente, la educación social como campo de estudio está constituido por y en la teoría, la práctica y la investigación, dando origen a la pedagogía.

¿̇Tiene sentido, entonces, una reflexión pedagógica, un discurso teórico, un proceso de investigación reflexiva y crítica sobre la educación? Cada quien podrá juzgar y responder por sí mismo. Nuestra apuesta es que sí lo tiene, siempre y cuando se trate de una reflexión (teoría) e investigación praxeológica a partir de la práctica educativa, práctica que es transmisión de contenidos culturales y capacidad para llegar a ser, práctica que permite comunicar a otro lo que se realizó (historia), lo que se está creando (presente) y lo que se pretende hacer (proyecto).

La pedagogía, como teoría, se introduce en el campo filosófico de los fines educativos (horizonte del deber ser), en tanto que, como práctica, transita por el sendero científico, como saber provisional y discutible, y ha de pensarse en construcción permanente (Bernabeu, 1997). Kant publicó, a fines del siglo XVIII, su libro pionero Über Pädagogik con lo que estaba fundando una ciencia, lo que fue rápidamente comprendido por otros pensadores de lengua alemana que siguieron sus principios en sus propias investigaciones; tal fue el caso de Pestalozzi, suizo de lengua alemana; Fröebel, alemán de Turingia y su contemporáneo Herbart nacido en Oldemburgo, alumno de Fichte y Schiller. Todos ellos escribieron sobre Pedagogía, consolidando una tradición intelectual que demoró en extenderse a otros continentes. Por el otro lado estaban los franceses, rivales tradicionales de los alemanes, que debieron aceptar la terminología y las propuestas metodológicas alemanas, dado que ellos no tenían nada equivalente; pero, en 1879, Alexander Bain publicó en París un libro pionero titulado La science de l'education, fundamentado filosóficamente en los principios positivistas de Comte. Sin embargo, la tradición iniciada por los alemanes era tan fuerte y tenía a su favor a personas de tal nivel que no resultaba fácil retarla. Después de la primera guerra mundial, los Estados Unidos entran al debate con su prestigioso educador John Dewey, quien favorece el concepto de Ciencias de la Educación, porque Pedagogía no era muy aceptada en inglés y en ese idioma son sinónimos educación y pedagogía.

La gran pregunta es en qué consiste el "saber pedagógico": ¿̇resulta legítimo como un saber diferente?, ¿̇no se aproxima a otros saberes: psicología, fisiología, sociología, ética? $Y$ esa problematicidad de limitar su propio campo es lo que autoriza a algunos a hablar mejor de "ciencias de la educación" que de pedagogía. Sin embargo, no podemos descartar la posibilidad de un saber diferente de otros, dado que los hechos educativos están ahí, de forma innegable, como hechos no reductibles a otros y necesitados también de reflexión crítica y de investigación.

Analicemos este esquema (basado en el de Fullat, 1983: 18): 


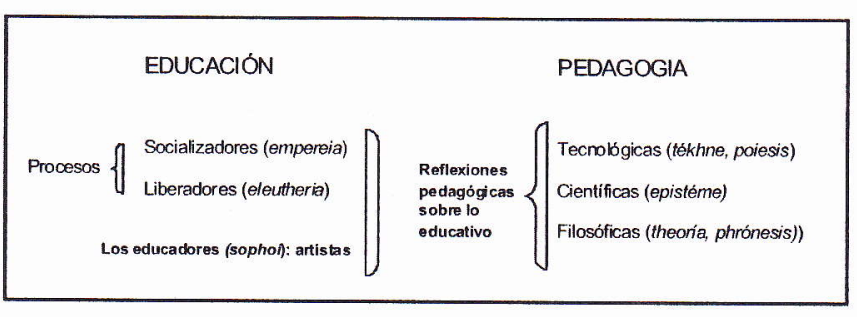

- Hay dos modalidades de procesos educativos: el "tradicional", que inserta en una sociedad sometiendo a la experiencia y al aprendizaje (la llamada "socialización") y el "deseable" pero poco frecuente, que libera, en tanto que la libertad es la condición del sabio.

- La educación es una obra de arte, los educadores son artistas (actores) que producen obras acabadas, perfectas (Fullat, 1983: 19). El que conoce de educación es un pedagogo; quien posee el "arte" de educar es un educador.

- Sobre dicho arte se han producido múltiples discursos que han generado saber (pedagogía) en torno a aquel. En la civilización occidental, han sido de tres clases:

- Tecnológicos ("saber hacer") que han dado como resultado las didácticas, las técnicas de aprendizaje, la organización escolar, etcétera.

- Científicos (ciencias de la educación), que comprenden secciones de las ciencias empíricas que dan razón, desde su punto de vista, de cuanto concierne a lo educativo.

- Filosóficos (filosofía de la educación), o consideraciones éticas, jurídicas, lingüísticas, estéticas, filosóficas, utópicas, etcétera, realizadas con el ánimo de saber y saber-decidir en temas educativos.

En síntesis, hay que decir que no basta con educar; hay que afrontar la tarea pedagógica: el educador ideal se cuestiona e investiga sobre su acción educadora (y llega así a ser pedagogo); igualmente, el pedagogo no-educador (teórico o investigador) no basta, pues aquello sobre lo que reflexiona es para ser comunicado en el quehacer educativo.

La pedagogía entonces, como disciplina teórica que reflexiona sobre la educación, tendrá que ver con el problema epistemológico primordial que es el paso del comprender al explicar: debe tener el rigor y la coherencia requeridos para construir discursos claros que puedan ser comprendidos y objetados; pero, igualmente, tiene que crear modos novedosos de explicar, enseñar, transmitir conocimientos que se consideran valiosos. Es decir, en pedagogía la dimensión metodológica y didáctica tiene la misma importancia que la dimensión teórica. Por eso la pedagogía se encarga de aportar el material de referencia explicativo, normativo y técnico para el diseño y desarrollo de prácticas educativas en cualquiera de los ámbitos en que se solicite su intervención, normalmente mediado esto por un proceso investigativo, crítico y reflexivo.

Pero no se puede olvidar que, como en cualquier otra disciplina, la pedagogía descubre en su quehacer los límites que impone la realidad: revelar algunas verdades a costa de desistir de resolver ciertos problemas fundamentales, de no poder excluir totalmente aquello de enigmático e inexplicable que su objeto de estudio contiene. $Y$ por otra parte, no se puede olvidar que las disciplinas son dinámicas, abiertas y sujetas a cambios que pueden modificar, incluso de modo significativo, el estatuto de una ciencia y/o una disciplina.

¿Podrá la pedagogía reconceptualizarse desde su papel mediador entre las múltiples exigencias de unos imaginarios sociales variables y el adecuado respeto a las diferencias de los sujetos? Esta cuestión plantea un desafío final a la pedagogía, a saber, "volver a centrar su objeto de estudio en las condiciones de posibilidad discursiva y material que deben darse en una sociedad o institución educativa para que ese trabajo de transmisión-adquisición de la cultura pueda acontecer de manera satisfactoria, eficaz y, ante todo, justa para todos los ciudadanos" (García Molina, 2003: 46). Porque el mundo está cambiando, la pedagogía tiene que continuar 
ideando los diversos modos como la educación puede continuar cumpliendo la misión que le corresponde. Como lo señaló Philippe Meirieu (1998), la pedagogía es proyecto, es la "esperanza activa del hombre que viene".

\section{B. LAEDUCACIÓN COMO FENÓMENO SOCIAL.}

Que la educación es un fenómeno social es una idea aceptada por todos los pedagogos. La sociología se ocupó de ello en sus inicios; Émile Durkheim lo dijo: "la educación común es función del estado social; pues cada sociedad busca realizar en sus miembros, por vía de la educación, un ideal que le es propio" (1998: 18) De ahí el papel político de la educación: la posibilidad de instituir un orden social concreto está en el modo cómo los ciudadanos conciben el rol de la sociedad, de sus estructuras y de ellos mismos al interior de dicho sistema de relaciones'; y esa comprensión sólo se logra mediante la educación. Se habla, entonces, de la construcción del espacio social (Bourdieu 2003: 34), es decir, de esa realidad impalpable, que no se puede mostrar ni tocar, conformada por las prácticas y las representaciones de los agentes de una sociedad. Esa construcción sólo es posible desde un proceso de donación de contenidos y experiencias de persona a persona, de un educador a un educando -un proceso comunicativo, pero situado, en términos de Habermas- desde el cual se van aprehendiendo los modos particulares de concebir el mundo que cada sociedad $y$, en consecuencia, cada cultura han asumido como propias.

Ahora bien, si lo social es el escenario que hace posible y restringe a la vez las relaciones entre individuos, los contenidos específicos de dichas relaciones, que permiten ver, comprender y explicar el mundo, al mismo tiempo que proyectarse en él, constituyen la cultura ${ }^{10}$, ese constructo simbólico, inconcluso y cambiante ("tesoro de signos" como lo llamó Turgot), compuesto de ideas, creencias, conocimientos, doctrinas, ideologías, herramientas técnicas y tecnológicas, obras de arte, asociaciones, leyes, reglamentos, pautas de conducta, etcétera, que puede transmitirse y heredarse.

El ser humano, ser social por naturaleza, se hace - o reinventa- en un proceso educativo que gira alrededor de la cultura, de su apropiación, reconstrucción y comunicación. Hanna Arendt (1993) entiende el proceso humano de aprendizaje a partir de la incorporación del sujeto al mundo, con la idea de que su naturaleza social no es suficiente para adecuarse a la vida organizada con otros, pues no se trata de organizaciones simples, sino complejas, plenas de historia, valores y significaciones, "en sociedades tan vastas como las nuestras, los individuos son tan diferentes los unos de los otros, que no hay, por así decir, nada de común entre ellos, salvo su cualidad general de ser hombres" decía Durkheim (1998: 18). La condición humana, según Arendt, se adquiere y desarrolla mediante la acción (práctica) y el discurso (teoría) que son, igualmente, la base de la diferencia y la diversidad humanas. Esta acción humana no es la actividad instrumental o técnica sino la praxis mediante la cual el sujeto emprende algo nuevo: el que el hombre sea actory la historia/cultura sea fruto de sus acciones no significa que no sea autor ni de sí mismo ni de la historia (Alvarez, 2000: 123).

Pues bien, una educación así entendida lo que plantea es la construcción de un "hombre nuevo", diferente del engendrado por la naturaleza, lo que busca es crear un ser social pues es la sociedad la que enseña a integrarse; es también,

9. El referente para entender, desde una óptica praxeológica, la sociedad y la política es Karl Marx quien defiende, frente al individualismo esencialista anterior al siglo $X X$, que la sociedad es una realidad que impregna al individuo y lo configura, redefiniendo su existencia, a la vez que ella misma es resultado de la acción recíproca (interacción/intervención) entre los hombres: el hombre es un ser social hasta el punto que únicamente puede individualizarse, ser él mismo, en la sociedad. Este pensamiento marxista va a caracterizar, según González (1996:26) el surgimiento de dos escuelas sociológicas que van a influir en toda la pedagogía contemporánea: la de lo social constituido (Durkheim) y la de lo social constituyente (Weber).

10. Lo que aquí se entiende por cultura se desprende de lecturas de autores como Berger, Bourdieu, Durkheim, Luckmann y Weber, que si bien expresan diferencias, en ellas subyace la certeza de que los humanos construyen la sociedad en la que viven, siendo ella misma quien suministra las condiciones para hacerlo: aquello que le es dado y desde donde el individuo puede comenzar a crear. 
según sus necesidades, la que dispone la cantidad y naturaleza de los contenidos culturales que debe recibir el sujeto y es la que atesora la conciencia alcanzada por las generaciones previas y la que la transfiere a las nuevas generaciones. "En la cultura, y en los imaginarios de época, habitan los elementos que permiten la comunicación entre individuos, la interpretación de lo humano y la base sobre la que construir nuevas posibilidades de vida y nuevas miradas sobre el mundo" (García Molina, 2003: 41).

La educación es, por una parte, la herramienta privilegiada de reproducción social, es decir, del mantenimiento del orden social. Pierre Bourdieu (2003) explica que el espacio social u organización de la sociedad se funda en un capital cultural, es decir en la herencia cultural -o más bien cosmovisión o modo de ver al mundo- que ese espacio social posee. La sociedad se organiza alrededor de valores acordados que son los que, finalmente, la explican como organización y colectivo. Así, el espacio social pasa a ser espacio simbólico, es decir, un conjunto de estímulos colmados de desigual significación que, convertidos en una especie de lenguaje, configuran las perspectivas, prioridades, ideologías, creencias e intereses de los integrantes del grupo social; de este modo la distribución del capital cultural deja construir un espacio social, que puede llegar a ser un lugar social, y la institución educativa, por razón del fomento de aquellas respectivas formas de concebir el mundo, ayuda a reproducirlo y mantenerlo a través del tiempo y de la historia.

Pero, igualmente, y aunque parezca contradictorio con lo anterior, la educación es una forma de participación social y un espacio vital de formación ciudadana. Por ello, nunca es algo políticamente neutral y siempre está en el centro de las tensiones que generan los diferentes intereses que se ciernen sobre ella. Entonces, ¿̇eproducir o transformar? Giroux (1992) manifiesta que el lenguaje de los teóricos reproductivistas vincula a las escuelas esencialmente con el discurso y las relaciones sociales de dominación: "Tanto en las versiones liberales como en las conservadoras, la teoría educativa ha estado firmemente atrincherada en la lógica de la necesidad y la eficacia, y ha sido mediada a través del discurso político de la integración y el consenso. Esto llega a ser claro si se reconoce que las nociones como conflicto $y$ lucha son minimizadas o ignoradas en el discurso tradicional de la teoría y práctica educativas" (1992: 102). Construyendo su pedagogía radical, Giroux ve en las teorías de la resistencia neomarxistas (Willis, Apple, Olson, etc) un desarrollo importante, aunque incompleto. En su propia teoría de la resistencia, el papel de la cultura, y concretamente del lenguaje, como elemento de los procesos de institucionalización es clave. Se trata de una corriente crítica capaz de ver las instituciones culturales y educativas como lugares en los que, dándose la reproducción, e incluso siendo ésta la tónica general, también se da la resistencia, el conflicto, la contradicción: "el discurso de democracia lleva inherente la idea de que las escuelas son lugares contradictorios: reproducen la sociedad general pero, al mismo tiempo, contienen espacios capaces de resistir la lógica dominante de esa misma sociedad" (Giroux, 1990: 35). Si esto es claro en la escuela formal, lo es mucho más en lo que se ha venido llamando educación social, educación para toda la vida y educación en el contexto de la vida cotidiana.

Desde esta perspectiva abierta y pluralista, se entiende que lo cultural y lo político tengan un papel esencial en la construcción histórica de la educación, en un proceso social de creación de significados. El educador es un trabajador cultural y la educación una cultura política. Las instituciones educativas, formales o no, son lugares sociales en donde, para practicar la resistencia, tiene mucho que ver la lógica de la moral y la violencia política de los grupos dependientes. Para Giroux, además, juega un rol primordial un elemento no siempre tenido en cuenta: la esperanza. "Finalmente, inherente a la noción radical de resistencia existe una esperanza expresa, un elemento de trascendencia, para la transformación radical, una noción que parece estar ausente en una serie de teorías radicales de la educación, que aparecen atrapadas en el cementerio teórico del pesimismo orwelliano" (1992: 145).

En un sentido adicional, si se considera (como se explicará mejor más adelante al describir la 
educación social) que la educación es acción social, y que la acción sociopolíica es educativa si quiere obtener efectivamente el calificativo de acción transformadora, los límites entre acción política y acción educativa, en sus sentidos más amplios, devienen difusos. El componente educativo de los movimientos sociales críticos y la acción de la educación emancipadora han de ser integrados en un único enfoque global. Freire plantea su propuesta de acción-reflexión" tanto en un contexto educativo que debe ser, al mismo tiempo, lugar de acción (el círculo de cultura con adultos) como en un movimiento social que asimismo debe ser educativo; el papel que incumbe al educador en un lugar es el que corresponde a quien actúa como "líder" social en el otro (y en ambos casos ha de superarse la dicotomía educador-educandos mediante el encuentro dialógico).

Pues bien, la educación es un fenómeno social no sólo por sus fines (integrar al sujeto al mundosociedad y permitirle transformarlos), sino también porque contribuye con sus practicas a la conformación de la realidad social y cultural de los distintos grupos humanos. La educación, como fenómeno social, sólo puede ser entendida a la luz de los acontecimientos históricos, políticos y sociales en los cuales se encuentra inmerso y a los cuales ayuda a configurar. $Y$ es que con Freire $y$ Giroux recuperamos el espacio de construcción de una educación liberadora, en donde los agentes de la educación deben ser "intelectuales" en el sentido de tener una práctica reflexiva y no repetidora, para convertirse entonces en agentes transformadores, y los sujetos de la educación deben ser gestores de su propio desarrollo y del de las comunidades de las que hacen parte.

Hay que evitar la trampa que asegura que el sistema educativo no puede lograr nada en tanto no cambie la sociedad; pero, igualmente, el extremo inverso: la ingenuidad de que todo se arregla con el estilo del profesorado, o con ciertos métodos innovadores de enseñanza. Hay, eso sí, que entender y vivir la educación como acción transformadora de las condiciones y de los contextos, la educación como acción ciudadana, colectiva y democrática: eso es construir la educación social y transformadora que necesitan los colectivos y las clases populares. Y para ello resulta necesario que, de forma crítica, la ciudadanía y los movimientos sociales asuman esta tarea como asunto propio y no como algo exclusivo de maestros profesionales y de estudiantes como individuos particulares.

\section{LA EDUCACIÓN: UNA ACCIÓN PARTICULARMENTE HUMANA.}

Fernando Savater (1997: 21 -35) dice, citando a Graham Greene, que "ser humano es también un deber". O sea, "nacemos humanos, pero eso no basta. Además tenemos que llegar a serlo"; y la posibilidad de ser humano únicamente se plasma mediante los otros, los semejantes, es decir, "de aquellos a los que el niño hará todo los posible por parecerse". Y "si, -continua Savater- como dice Jean Rostand, la cultura es lo que el hombre añade al hombre, la educación es el acuñamiento efectivo de lo humano alli donde sólo existe como posibilidad (...) La principal asignatura que se enseñan los hombres unos a otros es en qué consiste ser hombre". Aquí se entiende la necesidad de la educación como acción organizada de humanos sobre humanos.

Es que el aprendizaje humano, lejos de ser equivalente al aprendizaje animal, es un proceso complejo, colmado de variables que lo concretan y lo diferencian en cada persona. Mucho más si se entiende la educación desde la perspectiva del sujeto, pues ésta concibe que el formarse arranca de la historia de cada sujeto, unida y superpuesta a la historia de otros. Es en esa historia común que el sujeto registrará sus nuevos aprendizajes, o dicho de otro modo, en la construcción de los conocimientos compartidos por parte de sujetos $y$ agentes de la educación, en donde lo ya conocido se abre al examen y la investigación, en

\footnotetext{
11. Es necesario aclarar que el acto de conocimiento implica para Freire un movimiento dialéctico que pasa de la acción a la reflexión y de la reflexión de la acción a una nueva acción. En el contexto epistemológico del diálogo, se analizan praxeológicamente los hechos que ofrece el contexto real o concreto, implica un desplazamiento desde el contexto concreto, que proporciona los hechos hasta el contexto teórico, en el que dichos hechos se analizan en profundidad, para volver al contexto concreto, donde los hombres experimentan nuevas formas de praxis (Freire, 1990).
} 
un proceso social y no individual en el que se compara, contrasta y discute. Frente a la idea individualista de la educación, y también frente al sometimiento del sujeto a la imposición colectiva, han surgido propuestas que unen el desarrollo y autonomía personal con la convivencia social comunitaria y la participación democrática. Un clásico en esto, John Dewey (1916), plantea que en la educación que tiene como fin la cultura desaparece la contradicción aparente entre el desarrollo encaminado hacia el individuo o hacia la sociedad.

Se puede entender la complejidad del proceso de aprendizaje desde los contenidos que se transmiten, pero hay que asumir que no es únicamente eso: se aprenden contenidos culturales e información, y se desarrollan habilidades y competencias; sin embargo, también se aprende una manera de vivir, de ver al mundo, se aprehende una cultura, una cosmovisión. Pero ahí no termina todo: además es el aprendizaje de una sucesión de signos y significaciones, un aprendizaje de relaciones simbólicas, de un lenguaje específico, de un discurso concreto que da una perspectiva para comprender lo que se sabe y lo que se es capaz de hacer, tanto a nivel de productos culturales y tecnológicos como a nivel de relaciones entre personas.

Es por eso que el aprendizaje humano sólo es factible cuando se está en relación con otros humanos porque todo lo anterior sólo es posible aprenderlo de otros que lo hayan aprendido igual: de la cultura, que es obra especialmente humana. De este modo, la educación no es únicamente un conjunto sistemático de ideas, teorías y prácticas; se refiere también a un tipo de experiencias humanas que componen el hecho educativo. Sucesos cotidianos que tienen significado y sentido; un diálogo donde confluyen los ideales de formación y los implícitos y explícitos proyectos de vida de un colectivo. Lo cotidiano designa un conjunto de "vivencias", es decir, de entidades que suceden para y entre sujetos; no se trata de un conjunto de "hechos" (en el sentido objetivo clásico); son objetivas como las instituciones de Durkheim únicamente si pertenecen al campo de las subjetividades. $O$ sea que todo lo que puede ser llamado cotidiano sucede para una subjetividad que lo vivencia... se trata de vida cotidiana.

Ahora bien, lo cotidiano de una vivencia puede revelarse como lo común (la normalidad de la realidad) o como lo corriente (la obviedad del mundo). Pero hay dos formas de señalar lo obvio: como lo que no se ve y como lo que se da por visto; mientras todo ocurra como está previsto no hay nada por ver (en el sentido del ver que cuestiona, que pretende saber). La cotidianidad es pertinente justamente cuando lo social se opaca: momento cuando es más real que nunca toda la cotidianidad es actuación, juego de roles y menos visible; es tan indiscutible que su cara "social" brota oscurecida, en el sentido de que es ejercida sin ser reconocida. Así, vive en el mundo de lo obvio quien utiliza expresiones del tipo "sedice" como, por ejemplo: "Los costeños son flojos", "En el extranjero valoran mucho al profesional colombiano"... en todas ellas se transmite un dicho que construye una imagen de la realidad. Lo significativo es que, como opiniones que aparentan realidad, pueden ser dichas por cualquiera. Ausencia tajante de reflexividad, en que lo observado es observado como tal. Pero lo obvio puede ser tanto un "saber obvio" como un "deber obvio" (como "lo que corresponde"). La cotidianidad es el resultado de un esfuerzo de definiciones compartidas de lo que se instituirá como "la realidad" y, una vez hecho, sobreviene la realidad objetiva(da) en la que uno se mueve y hace "lo que corresponde" (Garfinkel, Berger, Luckmann). Reglas, leyes, órdenes a los que el sujeto debe responder. $Y$ para ello está la educación.

La obra de Peter y Luckmann (1986) redimensiona todo esto conectando con la pregunta por las instituciones y roles, conceptos fundamentales para los planteamientos socioeducativos que aquí se proponen. En este apartado se reasume su planteamiento en varias proposiciones:

- La sociedad es un conjunto de acciones normalizadas, distribuidas por actores asimismo tipificados. Acciones y sujetos tipificados fundarán el saber común esencial para orientar a los sujetos en su medio social. 
- La tipificación de las acciones saca del conjunto de los sentidos posibles, uno o algunos que quedan reconocidos como el sentido típico de la acción y de los actores. Este es el sustrato del sistema institucional de la sociedad, que se convierte así en su red de instituciones que vienen a puntualizar los roles que deben ser enseñados y apropiados.

- Las instituciones (= tipificaciones de acciones y actores) tienen una peculiaridad singular: son producidas por una labor social de interpretación y fijación de sentido (realidad producida), pero luego su origen se difumina y se vuelven "realidad" absoluta. Y esto se produce a través del mecanismo de transmisión intergeneracional que es la educación como proceso de socialización.

- Ya objetivada, la realidad producida requiere ser revestida por una segunda capa de verdad. Las legitimaciones, desde una máxima hasta los relatos simbólicos (religiosos, políticos, etcétera) son como un escrito de segundo orden que afirma la realidad con la valoración de "justo" o "bueno". Así quedan ligadas las instituciones y los diversos órdenes institucionales, afirmando un mundo donde los sujetos encuentran su identidad y sentido.

- Así, tipificación, objetivación y legitimación conforman los tres ejes de la construcción de la sociedad, vivenciable como realidad compartida. Como complemento, la socialización de los sujetos se concibe como el aprendizaje de las instituciones y la afiliación en el mundo que los relatos o universos simbólicos plantean. La socialización halla su mecanismo básico en la adquisición del "otro generalizado": el sujeto se forma como "uno" entre otros, reprimiendo el "yo" en el "se" que debe dominar quien ingresa a un mundo institucional.
- Dispuesta la genética de la verdad apropiada como realidad, la vida cotidiana queda sellada como el espacio en que las instituciones sociales se armonizan enteramente con los sujetos que las desempeñan. El mundo está en orden: la sociedad se reproduce y el sujeto halla el sentido.

- La cotidianidad llega a ser así, desde el punto de vista de la subjetividad, el mundo seguro donde no hay incertidumbre. Sólo resta regular las situaciones límites (muerte, duda, guerra, ilusión, etcétera) mediante los adecuados megarelatos que constituyen la visión de mundo y la ideal escala de valores con la que regirse.

Es fácil, entonces, entender que la cotidianidad es el espacio donde la ideología (percepciones o representaciones circulantes) opera como tal: la sociedad se hace conciencia registrando en la subjetividad el mapa de los caminos (correctos, incorrectos) y el orden de los nombres (en clases de equivalencia los nosotros y en géneros de orden - las jerarquías -). Anclado en dichas asociaciones y orientado por esos caminos, el sujeto reproduce la sociedad: no reflexiona la ley ni la realidad, simplemente las lee como verdad.

El hecho educativo, en este sentido, no se justifica por sí mismo, sino por su significado sociocultural y político. Pero es claro que esta tarea adquiere sentido y significado en la medida en que se comprende que los proyectos y realizaciones humanas tienen su propia dinámica, y es desde ésta comprensión que la educación, como rasgo específico de la cultura, surge como proyecto que convoca y aglutina a cada sujeto en particular y a la sociedad en su conjunto, y que puede ser algo más que socialización de los sujetos, siempre y cuando, con el aprendizaje de la reflexión rompa la obviedad natural y la cotidianidad pueda reproducirse cambiando. Sólo así el sujeto puede participar de algún grado de libertad y la responsabilidad constituirse como algo diferente al acatamiento. 


\section{LA EDUCACIÓN: CAMINO PARA EL DESARROLLO COMUNITARIO.}

El desarrollo, la educación y la participación han sido parte de la historia de la humanidad. Las sociedades del pasado y del presente han generado pautas para coexistir, para ensanchar las posibilidades de subsistencia de la comunidad, e inclusive, para optimizar la calidad de vida del grupo y de los individuos. Las tres nociones conforman las necesidades más importantes que todas las personas quieren satisfacer. Ciertamente, no significan lo mismo en períodos históricos distintos ni poseen el mismo valor para comunidades o culturas diferentes. El equilibrio entre los tres es débil y siempre implica tener en cuenta sus opuestos: el estancamiento (no desarrollo), la exclusión (no participación), la ignorancia (no educación). En todo caso, un modelo de desarrollo será el efecto de los diversos significados que cada grupo humano otorgue a estos conceptos.

La noción de desarrollo es, probablemente, una de las más debatidas en esta época de globalización económica; de polarización social, que excluye a una parte importante de la sociedad; de generación de nuevas pobrezas y de detrimento constante del medio ambiente. Entre otras, el concepto presenta estas dificultades: a) relatividad, en tanto que siempre se está en vías de desarrollo (personas, sectores, países); b) vaguedad, pues para entenderlo mejor, el concepto desarrollo siempre requiere de calificativos (físico, económico, ecológico...o integral, sostenible, sustentable, etcétera); c) posición ideológica, ya que tras esta noción hay siempre una visión acerca de cómo debe originarse y manifestarse (incrementar la producción, preocuparse de lo que la gente puede o no hacer). Es, entonces, un concepto vago, impreciso y relativo, que se usa fundamentalmente para introducir comparaciones o mostrar tendencias. Sin embargo, se da hoy un acuerdo generalizado: la perspectiva sólo económica del desarrollo es unilateral y restrictiva.

Es fácil ver, entonces, que las sociedades actuales se encuentran ante dos disyuntivas de desarrollo institucional. El uno entendido como "desarrollo sostenible", el otro como "globalización". Mientras este último se basa en el crecimiento económico sin límites y tiende a la concentración del poder en algunas naciones $y$ centros financieros, el otro pretende un compromiso por un crecimiento regulado seguido de una especie de "retroalimentación" que mitigue sus efectos sobre el medio ambiente y la desigualdad social humana. Es lo que señaló Carlos Fuentes, en la última página de su libro El espejo enterrado (1992): "Los Estados democráticos en la América Latina están desafiados a hacer algo que hasta ahora sólo se esperaba de las revoluciones: alcanzar el desarrollo económico junto con la democracia y la justicia social. Durante los pasados quinientos años, la medida de nuestro fracaso ha sido la incapacidad para lograr esto. La oportunidad de hacerlo a partir de hoy es nuestra única esperanza". ¿¿Será una visión utópica? Tal vez no, porque el desarrollo tiene que ver con diversas dimensiones de la vida humana: económicas, sociales, políticas, culturales y de relación con el medio ambiente, el entorno; y porque el desarrollo influye en todas esas dimensiones. Así como pueden mejorar las condiciones en ellas, puede haber desmejoramiento de otros aspectos. Ver el desarrollo solo desde una disciplina es algo parcial. La esperanza es que una mirada interdisciplinaria identifique y descubra relaciones y conexiones que desde una sola disciplina no son visibles, para establecer así diálogos que permitan un mejor entendimiento $y$ una mejor acción.

El otro término en cuestión es el de comunidad. Si bien el uso más corriente es como sinónimo de sociedad, con él se puede designar realidades diferentes, tales como: una localidad o área geográfica (territorio), un grupo estructurado a través de un conjunto de relaciones sociales y un conjunto de personas que comparten un sentido de pertenencia. Hay acuerdo en considerar que el término "comunidad" es uno de los más confusos del vocabulario actual al ser profundamente polisémico. Con todo es claro su valor como referente sustancial para la conciencia, la ciencia y la experiencia humanas. Sin entrar en mucho debate, podemos afirmar el papel de la comunidad en una doble perspectiva: por un lado, la reconstrucción de la historia social, a partir de la cotidianidad; por otro, la búsqueda de 
nuevos horizontes para el bienestar de las personas y el desarrollo de los pueblos. Dos cuestiones fundamentales, desde un pensamiento crítico o una pedagogía social, para la reflexión y la praxis.

Al margen de otras consideraciones, es razonable plantear que el concepto de comunidad por el que se opte debe ser congruente con tres factores: una localidad geográfica compartida, unas relaciones y lazos afectivos comunes y unas pautas específicas de interacción social. La comunidad es, en síntesis, una unidad de vida que se distingue por la adhesión que mantienen sus integrantes, con un sentido de la ubicación y la pertenencia que no se entiende sin la existencia de niveles mínimos de solidaridad y de intercambio de significados (Rezsohazy, 1988:49-50). Dicho de otro modo, es un "ecosistema social" con estas cualidades:

- Existencia de un grupo humano cuyos miembros se reconocen entre sí admitiendo que forman parte de una realidad construida a partir de su presencia y sentimiento de pertenencia.

- Existencia de una base geográfica o espacial que soporta las relaciones humanas (territorio que paulatinamente es delimitado: fronteras).

- Adecuación a una configuración infraestructural, de base económica, asociada a modos particulares de producción y de vida (sistema económico de la comunidad).

- Mantenimiento de relaciones interpersonales e interacciones sociales constantes en términos de socialización, comunicación, emotividad, ayuda, etcétera (tiempo histórico común y estable).

- Presencia de estructuras y organizaciones sociales legitimadas públicamente como necesarias para el desarrollo de la vida cotidiana (instituciones, recursos...).

- Existencia de un sentimiento intransferible de pertenencia, referido a cada individuo y a los núcleos intermedios en que se integra (familia, asociaciones...).

Al integrar las dos nociones en el concepto desarrollo comunitario ${ }^{12}$ igualmente encontramos múltiples definiciones que se diferencian según se ponga el acento en el desarrollo o en la comunidad y según la idea que se tenga de ambas nociones. Una de las más elaboradas es la de Rezsohazy (1988:18) para quien "el desarrollo comunitario es una acción coordinada y sistemática que, en respuesta a las necesidades o a la demanda social, trata de organizar el proceso global de una comunidad territorial bien delimitada o de una población-objetivo, con la participación de los interesados". Siguiendo los planteamientos de Cabello (2002, 174s), el desarrollo comunitario así entendido tiene las siguientes características:

- La finalidad es el desarrollo integral y el progreso global, que no se reduce al simple crecimiento económico, sino que promueve a todos los hombres y a todo el hombre.

- La comunidad es agente, actor, de su propio desarrollo; de ahí la necesidad de definir dicha comunidad en términos geográficos y de relaciones sociales.

- Responde a las necesidades y/o demandas de la población; lo que significa que implica una investigación anterior sobre las mismas, así como sobre los recursos de que se dispone.

- Busca unos objetivos precisos y contextualizados, espacial y temporalmente; es decir, se trata de una acción localizada, planeada, regulada y sistemática.

12. El desarrollo comunitario, como se verá más adelante, es una de las vertientes de la educación social y tiene que ver con conceptos como educación comunitaria, educación para el desarrollo y educación popular. 
- Los objetivos definidos han de ser priorizados sin perder de vista la globalidad ni los medios disponibles.

- La planeación debe incluir el control y la evaluación permanente que permita socializar los progresos, consolidar los procesos e introducir los cambios requeridos.

El desarrollo comunitario se asocia normalmente a una metodología de trabajo con personas, grupos, regiones y países desfavorecidos; sin embargo, es considerada, en círculos especializados, como "una de las formas de la educación social". Y es que la relación entre las dos expresiones es inevitable, pues como lo señala Quintana (1991:12) "A veces se ha considerado la educación comunitaria como una educación activa de la comunidad: es decir, aquella educación que da la comunidad (...) Pero normalmente se llama educación comunitaria a la educación pasiva de la comunidad, o sea, aquella educación que es dada a la comunidad a fin de que pueda vivir eficientemente como tal; es la educación que capacita a los individuos para participar positivamente en la vida de la comunidad".

Haciendo un poco de historia, se puede señalar que, con el trasfondo de la industrialización naciente, aparecen las primeras experiencias de desarrollo comunitario en Londres (1884): acciones sociales y culturales para la comunidad buscando mejorar su calidad de vida. Experiencia que se expande pronto por toda Europa $y$ Norteamérica. A comienzos del siglo XX surgen iniciativas profesionales lideradas por trabajadores sociales tendientes a mejorar la salud y el bienestar de las comunidades. Con ello se dan los pasos hacia la adopción de un "modelo" de organización comunitaria, entendido como un proceso de ajuste entre los recursos del bienestar social y las necesidades de las comunidades. Tras la crisis de 1929, las instituciones públicas amplían su intervención con objetivos bastante pragmáticos. La "organización de la comunidad" adquiere carta de ciudadanía (aunque en Latinoamérica y Europa se expande más lentamente). Tras la segunda guerra, la lucha por la liberación nacional en países colonizados contribuirá a afianzar y a suscitar la necesidad de estrategias comunitarias, cada vez con mayor conciencia política: aparecen los modelos alternativos de desarrollo, de carácter endógeno y autosuficiente, ecológicamente solventes y basados en transformaciones sociales objetivables: se busca impulsar actividades que busquen el desarrollo de la comunidad, a través del impulso de la iniciativa individual y comunitaria, y de la decidida participación de ambas instancias. La expresión "desarrollo comunitario" tiene un claro precedente en el concepto de "educación de masas" y una alta importancia en la educación social promovida por las Naciones Unidas entre 1945 y 1965. Pero los cambios socioculturales que se producen a finales de los sesenta obligarán a un replanteamiento de los modelos de intervención adoptados hasta ese momento, considerados funcionalistas y adaptativos. Surgirán nuevos modelos que buscan transformar las condiciones de existencia desde, con y para la comunidad: modelos participativos y autogestionarios, preocupados por armonizar las relaciones entre las personas y los ambientes.

Todo lo planteado hasta aquí conlleva una nueva concepción de lo educativo y lo comunitario que se hace visible en aspectos como:

- Pensar los problemas educativos en su relación con los problemas del desarrollo de la vida local y cotidiana.

- Construir programas de educación social que partan de las necesidades locales de modo que se configure una educación inter y transdisciplinar encaminada al desarrollo global y sostenible de las realidades locales y cotidianas.

- Replantear las políticas socioeducativas, en sus niveles y recursos, ya que el uso de las oportunidades educativas de lo cotidiano y local modifica el papel de las instituciones educativas y el quehacer y la formación de los educadores requiere teorías y prácticas nuevas. 
- Involucrar a la población de un territorio, como actores-agentes y organizaciones que, simultáneamente, gestionan la educación y la cultura y se benefician de sus efectos, extendiendo los públicos de la formación y considerándolos sujetos y destinatarios de la misma.

En síntesis, las comunidades sólo pueden alcanzar un estado de desarrollo integral cuando el proyecto social contempla los procesos de crecimiento económico y de desarrollo del pensamiento, de la creatividad y del espíritu crítico de todos y cada uno de sus miembros como un sistema en estrecha interacción e interdependencia: el crecimiento económico en función del desarrollo de las personas y de su pensamiento y el desarrollo del pensamiento en función del crecimiento económico. El desarrollo humano y social integral es inconcebible, entonces, sin procesos educativos críticos, creativos, innovadores de los que participen todos en la comunidad. La educación del pensar y del hacer tiene que llegar a todos, superar los estadios operacionales y ser significativa y pertinente para todos. Desde esta perspectiva el desarrollo es entendido, entonces, como el proceso educativo social que permite a las personas y comunidades utilizar su potencial, adquirir confianza en sí mismas y llevar una vida digna y realizada, librándose del temor a las carencias y a la explotación.

\section{E. EDUCACIÓN Y COMPROMISOSOCIAL.}

Esta es una cuestión que tiene muchos ángulos. Uno - diferente de los anteriores y tal vez fruto de ellos - es el de la finalidad última de la educación y de todo proceso de aprendizaje. Ya Foucault (1979, citado por Martínez 2001) mostró que todo discurso es un efecto de poder organizado mediante reglas anónimas, mediadas históricamente y determinado por un tiempo y un espacio. La institución educativa - como lo dice
Martínez (2001: 96) - es una formación discursiva, es decir, un conjunto de prácticas discursivas que logran cierta institucionalidad. Ahora bien, este discurso llamado escuela, al mismo tiempo que pretende construir un armazón conceptual racional que ordene ideológicamente la realidad social (lo que Bourdieu llama capital cultural), busca -para realizar el itinerario que se ha impuesto a sí misma- distribuir y reproducir relaciones de poder. Pero esto hay que mirarlo en una doble dimensión: lo mismo que puede hacer de la institución educativa un discurso de exclusión, la puede hacer un discurso de integración. Y esta dialéctica es lo que conforma no sólo la práctica educativa, sino asimismo el diseño curricular: la educación no sólo reproduce y transmite las formas de relación de los diferentes actores sociales, sino que es también el lugar en donde se encuentran y se generan formas distintas de resistencia y oposición.

Becerril (1999), siguiendo a Althusser, explica este fenómeno desde dos hechos: el primero es que "en las condiciones de orden social, el desarrollo de las fuerzas productivas necesita a las organizaciones escolares como condiciones de producción al mismo tiempo que producen" ( $p$. 69); y el segundo, es que esta reproducción no es involuntaria, sino compleja y puede abrigar distintas formas de resistencia, las que este autor ahora apoyado en Apple ${ }^{13}$ - Ilama contradicción: es decir, la posibilidad de que en "la organización escolar, los trabajadores creen ciertas condiciones autónomas para ejercer el control de su trabajo, que se configura en un especie de contraorganización con relaciones informales que desafían a la norma, ya que se valen de ingenio y creatividad cultural para tomar distancia de la determinación" (Becerril 1999: 78)

Así, exclusión e integración son dos potencialidades del quehacer pedagógico, resultados del proceso de aprendizaje que realiza cada persona en tanto miembro de un grupo social. Esto, que igualmente es obra humana, cuestiona el sentido que, como macroestructura

13. Profesor norteamericano de Enseñanza y Estudios de Política Educativa en la Universidad de Wisconsin. Su trabajo crítico se ha centrado en el análisis de los procesos educativos a partir del currículo escolar. Su análisis resulta de gran interés, en la medida que destaca la contradicción de una sociedad que se define como de la información y el conocimiento, pero que en los procesos de socialización muestra un giro conservador muy acentuado. 
social o como decisión individual, hay que darle a la acción educativa; lo que adquiere mayor relevancia al asumir que lo que busca la educación es, precisamente, ser una herramienta de integración social, es decir, desarrollar la capacidad del sujeto educativo de ser parte, de modo autónomo, activo y solidario, de los procesos sociales en los que le corresponde desplegarse. La idea básica es que se logre formar personas - ciudadanos, según Magendzo (2003) solidarios, conscientes y críticos, capaces de emprender "algo nuevo" (Arendt 1993: 208), es decir, de recrear al mundo mediante acciones plenamente conscientes y responsables, a la vez que transformadoras de las realidades sociales. Es lo que Bronislav Geremek (1996) Ilama cohesión social: el respeto de la dignidad de la persona humana y la generación de vínculos sociales en nombre de la solidaridad para integrarlo a los otros, a los diferentes, y preservarlo de la exclusión y la incomunicación a los que el no saber -es decir, la ignorancia- los condena.

Obviamente todo esto implica una decisión del individuo sobre las alternativas que le proponen los discursos en juego: no se puede estar al margen de esto, en especial si el individuo es un agente educativo, es decir, el responsable de que un grupo de sujetos aprendan. El quehacer docente implica asumir una posición en la medida en que es el medio a través del cual llegan a los sujetos los contenidos culturales; es el maestro quien, bajo la influencia de un discurso cultural y político, resuelve lo que los sujetos requieren para hacer parte de la estructura social. El va a ofrecerles el capital cultural que necesitan para desempeñar las funciones que les corresponden en las diversas redes sociales donde participan; pues bien, para que esto se dé, el agente educativo debe haber definido para sí -y para sus alumnos- una posición frente al contexto históricocultural que enfrenta, 0 , dicho de otro modo, debe darle un sentido a su labor como educador. Posición implica tomar partido en la docencia, frente a lo que se enseña y a quien enseña.

Es una falacia creer que la educación pueda ser apolítica o neutral ideológicamente: una teoría educativa es "una teoría política en el sentido de que se deriva del consenso que se refiere a la distribución del poder dentro de la sociedad: a quién se educará y para cumplir qué roles" (Bruner, 1987: 112). Si un autor nada radical como Bruner lo afirma, es fácil pensar que quien lo niega tal vez tiene algo que encubrir, o bien no ha analizado que lo que supone es también ideología, más introyectada en tanto menos reflexionada, y producto de intereses reales que evitan mostrarse explícitamente. Obviamente no se trata de instrumentalizarla, sino al contrario, de reconocer que, como todo proceso discursivo y comunicativo, la educación se enraíza en principios ideológicos -no necesariamente una ideología política, sino una cosmovisión o concepción del mundo-y que éstos le otorgan su finalidad y sus métodos.

Lastimosamente esta conciencia sobre el compromiso social del educador no siempre existe. Las reformas educativas traen cambios de paradigmas a nivel social, no porque signifiquen siempre revoluciones educativas, sino porque implican concepciones de persona, de sociedady de mundo diferentes. La realidad nos muestra un mundo convertido en un "sistema global sobre el cual el capitalismo, en sus diversas formas, ha tejido una compleja red de relaciones económicas, culturales y políticas" (Martínez 2001 : 92). Esto, en el caso de la educación, se nota en el discurso sobre la profesionalización docente, el que lejos de pretender una reivindicación social de la profesión docente propone una reformulación del perfil profesional, alineándolo a los nuevos tiempos, convirtiendo al docente en un funcionario a cambio de cierta seguridad y a costa de la pérdida de control sobre los diversos niveles de concreción de la práctica docente.

Ante este horizonte, hay que reconceptualizar el compromiso social de la educación y del educador, pues, como lo señala Martínez (2001: 95) "el compromiso radical de la escuela con la educación del ser humano no puede eludir su posición crítica con las políticas de injusticia y desigualdad. Ésta debe seguir siendo una cuestión básica en todo educador". La educación debe ser una liberación (Freire), un proceso que ayude a la persona y a la comunidad a ser autónoma frente a aquello que las limita, que las emancipe de sus determinismos (Habermas, Groundy), para que puedan construirse a sí 
mismas. Desde esa perspectiva el docente, como agente necesario del proceso educativo, debe concretar un compromiso permanente con el proceso de enseñanza y con su práctica docente, de modo que responda a lo que la realidad le pide sobre la formación de los sujetos $y$, como consecuencia de esto, sobre la construcción de la sociedad y la cultura; compromiso que supone una toma de conciencia y trae como consecuencia una acción pedagógica centrada en una situación formativa, es decir, un espacio de práctica educativa mediadora entre sujetos y dispositivo pedagógico que abarca la trama de relaciones que fundan, tanto la relación entre actores (interacción pedagógica) como la interacción entre saberes y contenidos culturales (relación significante).

Esta reconceptualización de la educación para que asuma y explicite su compromiso social, sobre todo en América Latina, se inscribe en la tradición del pensamiento crítico (y de las teorías pedagógicas que surgen del mismo) que sale al encuentro del pensamiento único, porque, como bien lo dice Rodríguez en su introducción al libro de Boaventura de Sousa Santos (2003):

El comienzo del siglo XXI ha presenciado el renacimiento de la teoría social crítica y del pensamiento progresista con proyección política en América Latina. Tras varios años de relativo silencio, debido, entre otras cosas, al desencanto producido por la caída de la cortina de hierro, que le dio la oportunidad en la década de los años noventa a tantos intelectuales críticos y políticos progresistas, entre ellos varios de los que se preciaban de ser más radicales, de pasar a defender ideas más seguras y rentables con el mismo dogmatismo con el que proponían visiones contrarias en los años setenta y en los ochenta, nos encontramos hoy con una amplia gama de trabajos académicos, movimientos sociales y propuestas políticas que representan una nueva forma de pensar y ponen en próctica los valores de la igualdad, la libertad y el reconocimiento de la diferencia.

No se puede olvidar que el verdadero cambio social llega de la mano de una práctica reflexionada y transformadora, de una praxis social. Práctica unida a un proyecto político crítico y reivindicativo que tiene por esencia esclarecer el mecanismo del control del saber. Bajo estos planteamientos, la praxeología puede considerarse como una estrategia de cambio social al servicio de una innovación educativa que conduzca al desarrollo integral de las personas y comunidades.

\section{F. EL QUEHACER PRAXEOLÓGICO EN EDUCACIÓN.}

La praxeología ${ }^{14}$ se entiende como un discurso (logos), construido después de una seria reflexión, sobre una práctica particular y significante (praxis), como un procedimiento de objetivación de la acción, como una "teoría de la acción"; por el tipo de análisis que realiza pretende hacer que dicha praxis sea mas consciente de su lenguaje, de su funcionamiento y de lo que en ella está en juego, sobre todo del proceso social en el cual el "actor" o "practicante" está implicado y del proyecto de intervención que construye para cualificar dicho proceso; todo esto con el fin de acrecentar su pertinencia y su eficacia liberadora. Ella es el resultado, entonces, de un análisis empírico y de un discurso crítico: la praxeología designa, desde el principio, una reflexión práctica sobre los principios de la acción humana y de sus técnicas, pero busca, igualmente, los principios generales y la metodología adecuada para una acción eficaz y pertinente.

Cuando un profesional, tratando de resolver y comprender una situación problemática, se esfuerza por observar el efecto de sus propias acciones y prácticas, para mejorarlas en el momento de volverlas a realizar, se convierte en lo que Donald Schön (1998) Ilama un profesional reflexivo. ¿̇En qué consiste esta reflexión en la acción que realiza dicho profesional? En la lógica del pensamiento de Schön hay que entenderla como el proceso mental que permite a un profesional adaptarse a cada situación que se le

14. Para presentar la praxeología y facilitar una comprensión de lo que constituyen sus grandes ejes metodológicos, nos inspiramos en el capítulo cuarto del libro de Juliao (2002). 
presente en el ejercicio de su profesión; una especie de dialogo continuo entre él y los acontecimientos de su practica profesional. Al usarla sistemáticamente, el profesional puede aumentar la eficacia de sus intervenciones, desarrollando progresivamente una especie de modelo de intervención a la medida. Schön afirma que esta reflexión es, también, una reflexión sobre la acción. Así, en una situación que parece difícil de controlar, el sugiere que el profesional «reestructure el problema y, en esta nueva tentativa [que Schön Ilamará] una experiencia de estructuración, el tratará de imponer su voluntad" (Schön, 1998: 91).

Yves St-Arnaud y Alexandre Lhotellier, investigadores canadienses, reafinaron esta teoría de Schön y la llamaron praxeologie, en tanto que pretende transformar la investigación asociando el saber (logos) y la acción (praxis). Ellos la definen así: "La praxeología es un proceso investigativo construido, de autonomización y de conscientización del actuar (en todos los niveles de interacción social) en su historia, en sus practicas cotidianas, en sus procesos de cambio y en sus consecuencias" (1994: 95). La praxeología proporciona instrumentos prácticos para determinar si la acción que se realiza es eficaz y cuáles serían las otras acciones de mejora a emprender. Ambos autores sostienen que la acción, más que ser simplemente la aplicación de un conocimiento, puede ser la fuente misma de este conocimiento. Además, como el procedimiento praxeológico intenta reducir las fronteras (dualistas o de otro tipo), puede servir en donde se lo desee aplicar. El dialogo entre el saber y la acción puede llevarse prácticamente a todas las situaciones.

Ahora bien, el quehacer praxeológico cumple una cuádruple función de conservación, de enriquecimiento, de gestión y de apropiación de los saberes de la práctica, función similar a la de los knowledge managers ${ }^{15}$. A diferencia del profesional práctico, el profesional reflexivo o praxeólogo se interesa más por las prácticas eficaces, por el "saber-hacer" que implican, que por los resultados de las mismas; a diferencia del práctico comprometido con la complejidad de lo real, el praxeólogo tiene que realizar un ejercicio de abstracción, de pensar por separado aquello que no está separado: se trata de descomponer la práctica (y sus procedimientos) en tantas fases como sea necesario para comprenderla $y$, enseguida, conducirla o reconducirla con pleno conocimiento. Este desplazamiento de lo concreto vivido o percibido (la práctica o la observación de la práctica) a lo concreto pensado, para retornar a lo concreto construido, y de ahí a lo concreto aprehendido, es el quehacer fundamental de la praxeología (Juliao, 2002). Es una revalorización de la práctica que, como lo dijo Bourdieu (2003a: 75) "siempre está subvalorada y poco analizada, cuando en realidad, para comprenderla, es preciso poner mucha más competencia técnica, mucha más, paradóiicamente, que para comprender una teoría".

Hay que tener en cuenta que la praxeología no es exactamente el análisis de las prácticas, sino el análisis de la praxis. La razón práctica no tiene los mismos objetivos que la razón praxeológica: aquella se enfoca a la eficacia de las acciones, al logro de lo planeado; la praxeológica indaga y construye los saberes de la práctica mejor adaptados para gestionar una acción $y$, en últimas, intenta construir una teoría general de la praxis. La lógica de la acción (praxis) se articula con la del conocimiento (logos); y la clásica oposición entre teórico y práctico se transforma en una complementariedad dialéctica entre saberes y saberes de la acción, favoreciendo un movimiento en espiral entre lo vivido, la práctica y el pensamiento, que termina haciendo de esa práctica una praxis.

La praxeología parte de la idea de que, desde la praxis y la práctica la distinción entre los dos conceptos se hará más adelante -, se pueden construir saberes; se puede extraer la estructura de una experiencia considerada interesante $y$ pertinente, en función de cierto número de

15. Concepto anglosajón para designar a los profesionales que contratan ciertas empresas con la tarea de evaluar, estructurary redistribuir el "saber hacer" y el capital intelectual de las mismas. Profesionales que deben poseer competencias como: capacidad de escucha, facilidad de relación, diplomacia, carisma, facilidad de comunicación, espíritu de síntesis, aptitud para compartir información. 
objetivos que ella se dio, o de un cierto número de resultados esperados; de ella se puede extraer lo esencial y eso esencial puede ser transferido en un proceso netamente educativo. Eso esencial es la racionalidad interna de la praxis, sea que haya sido bien controlada por los actores mismos o que haya sido empírica y espontánea.

Cuando se trata de fijar el quehacer praxeológico en educación (mucho más, si se trata de la educación social como práctica específica) hay que considerar los cinco desafíos siguientes, que se convierten en líneas de un proceso de investigación praxeológico sobre lo educativo:

- La elaboración de saberes de la práctica educativa, específicos y transferibles (dimensión técnico-científica). Este es el corazón del quehacer praxeológico en educación, con el que se busca definir los elementos de la práctica para trazar las perspectivas de investigación, sin ignorar lo que ya se ha hecho. Es responder a la pregunta: ¿̇dónde nos encontramos hoy en educación?

- La gestión más pertinente y eficaz de las acciones (dimensión pragmática). Este sería el primero según el orden de los fines de la educación: se trata de la eficacia y de la credibilidad $y$, desde ahí, de la legitimidad de la educación. Los objetivos deben ser repensados, los métodos y procedimientos tendrán que ser evaluados, las estrategias y medios de control y organización deberán ser reorientados.

- La emancipación política y social de estos campos de práctica (dimensión política). Este sería el primero desde el orden del compromiso social y de la urgencia de la educación. Y el hecho es que falta mucho: la educación tiene aún mucho de dependencia y de precariedad; poco de autonomía. Los discursos contra la instrumentalización de la educación no bastan; la construcción de un pensamiento racional y riguroso sobre la acción educativa (es decir, una praxeología) puede ayudar a liberarla como campo de práctica autónomo.

- La comprensión del surgimiento y constitución de esos campos de práctica (dimensión histórica). El campo de las prácticas educativas es complicado; mucho más el de las prácticas en educación social. El planteamiento praxeológico, que se interesa tanto por los procedimientos de intervención educativa como por las condiciones sociales, políticas e ideológicas del surgimiento y desarrollo de las estructuras educativas, aclararía y permitiría, probablemente, comprender las rupturas y adhesiones, así como las dificultades de la educación para constituirse en campo autónomo de práctica.

- La formación de los actores comprometidos en esos campos de práctica, sus contenidos y métodos (dimensión formativa). La cuestión es sobre cómo los saberes teóricos y disciplinares pueden utilizarse para formar en el "saber-hacer", para trabajar la realidad, construir los problemas y resolverlos, permitir la evaluación crítica de los resultados y de los instrumentos utilizados. $O$ dicho de otra forma: Żcómo los saberes pueden, en contacto con la realidad, volverse procesos y procedimientos a la manera de estrategias de acción? Es esa zona oscura entre saberes teóricos y prácticas lo que la praxeología tiene que esclarecer para que aquellos $y$ estas no permanezcan separados, como saberes sin objeto (conceptos abstractos) o prácticas sin conciencia, condenadas a la repetición mecánica.

Antes de avanzar más en esta línea, es necesario aclarar la distinción que aquí se hace entre práctica y praxis. Usaremos un ejemplo por su simplicidad pedagógica.

Cada mañana, cuando me despierto, preparo un café sin que ello me exija una real actividad 
intelectual; tengo necesidad del café para despertarme plenamente y sí hacerlo implicara un trabajo intelectual y práctico complejo, nunca lograría preparar mi café y, por tanto, no me despertaría realmente. Prepararlo es de esos actos automáticos y programados, lo que me permite dejar volar mi imaginación y mi atención hacia otras cosas: cómo amaneció el día, el trabajo que tengo por delante, mi último sueño...Preparar el café es ciertamente una práctica, pero que se ha vuelto espontánea y de algún modo, incorporada en mi cotidianidad, lo que no significa que, en ocasiones, pueda fracasar (por ejemplo, puedo estar atrasado y no alcanzo a prepararlo, o puedo no encontrar con qué prepararlo). Es, lo que Bourdieu (1972) Ilama un habitus ${ }^{16}$ ampliamente determinado por la educación y la cultura. Ahora bien, la mayor parte de nuestras actividades cotidianas son de este tipo de prácticas espontáneas, adquiridas, interiorizadas, donde la actividad intelectual es casi nula.

Imaginemos ahora que soy un hotelero profesional, preocupado por el bienestar de mis clientes y por su fidelidad a mi negocio. Yo voy, entonces, a preocuparme de modo especial por la preparación del café y de las demás bebidas del gusto de los clientes. Tendré que utilizar mi inteligencia práctica, adaptar pertinentemente mis medios a los fines deseados, realizar mejoras y rectificaciones, desconfiar de mis automatismos, probablemente adquirir nuevos conocimientos. Este otro modo de preparar el café es de otra naturaleza: se trata de una praxis muy diferente de la práctica espontánea, que requiere de otra postura, que implica una reflexión intelectual y que pone en juego métodos, procedimientos y tácticas regularmente repensados, en el contexto de una profesión concreta.

La praxis es, entonces una práctica sensata, no espontánea sino pensada, que supone un procedimiento intelectual y no una simple repetición mecánica. Obviamente, no todas las prácticas cotidianas tienen que ser convertidas en praxis; de ser así, la vida sería imposible.
Praxeología y praxis están íntimamente ligadas, aunque no obedezcan a las mismas lógicas. La praxis es la ejecución de técnicas en coherencia con finalidades (tecnología); la praxeología es la construcción de saberes de la acción (ciencia). El objeto principal de la praxeología es la elaboración, experimentación y validación de modelos de acción ${ }^{17}$ que sean útiles para la gestión de la praxis: permite formalizar, validar y programar lo que generalmente de hace de modo espontáneo, intuitivo y empírico. Ahora bien, para lograrlo, el enfoque praxeológico que se sitúa en el cruce de la investigación teórica, de la investigación acción, de la investigación "aplicada e implicada", siendo, además, un método multireferencial y pluridisciplinario, supone cuatro fases o momentos, así:

\section{LAFASE DEL VER}

Esta es una fase de exploración y de análisis/síntesis (VER) que responde a la pregunta: ¿̇Qué sucede?; etapa fundamentalmente cognitiva donde el educador/praxeólogo recoge, analiza y sintetiza la información sobre la práctica educativa, tratando de comprender su problemática y de sensibilizarse frente a ella. En esta primera etapa la observación condiciona el conjunto del proceso : retomando los datos, se trata de establecer una problemática que, por una parte, supone que la práctica, tal como es ejercida, puede mejorarse, $y$, por otra parte, exige una comprehensión (una "segunda mirada") que no aparece espontáneamente y que implica un segundo momento. Las preguntas planteadas al observador se resumen así: ¿Quién hace qué? ¿Por quién lo hace?, ¿Con quién? ¿̇ónde?, ¿Cuándo? ¿̇Cómo? ¿̇Por qué lo hace?

Es, pues, la fase empírica o experimental, según sea que nos encontramos ante una práctica educativa espontánea e intuitiva, 0 , al contrario, ante una praxis educativa claramente pensada y

16. Este concepto clave de Bourdieu se refiere al conjunto de disposiciones adquiridas, permanentes y transferibles que permiten actuar, percibir, sentir y pensar de un cierto modo. Son disposiciones incorporadas o interiorizadas a partir del trabajo educativo prolongado (socialización, apropiación...).

17. Se habla de modelos de acción en tanto que saberes transferibles y utilizables por otros que permiten a quienes realizan la práctica clarificar la forma como definen, gestionan, controlan y evalúan la acción. 
controlada en su desarrollo. En ambos casos, el educador/praxeólogo está frente a una acción, sea práctica espontánea o praxis, de la cual debe comprender sus elementos, su racionalidad, su desarrollo en el tiempo y su eficacia en función de los objetivos, a veces mal o incluso no formulados $o$, al contrario, claramente definidos.

Si bien el objetivo praxeológico es el mismo en los dos casos (a saber, construir saberes y modelos de acción transferibles), las dificultades a las que se verá enfrentado el educador/praxeólogo y los métodos de comprensión que deberá adoptar, no van a ser los mismos. En el caso de las prácticas educativas espontáneas e intuitivas, las más frecuentes, tendrá que interactuar con practicantes que no podrán fácilmente elaborar la racionalidad de una acción que ellos no han construido formalmente; su trabajo será, entonces y a la vez, descriptivo, intuitivo, interpretativo, es decir, comparable al del etnógrafo que investiga, detrás de las prácticas, el "sentido oculto" que los actores mismos no alcanzan a producir. Muy probablemente encontrará pocos documentos escritos que definan los objetivos, las metodologías y los medios, que describan las fases del trabajo o que prevean las formas de control y evaluación; todo esto, obviamente, no quiere decir que los modos de acción que se estén ejecutando no sean pertinentes o no merezcan ser "modelizados".

Al contrario, en el caso de una acción educativa que se presente como praxis manifiesta, elaborada y reflexionada, el educador/praxeólogo tendrá a la mano datos que apoyarán el proceso de análisis/síntesis: documentos escritos, discursos elaborados por los practicantes, resultados de evaluaciones $y$, en ciertos casos, usuarios asociados a la acción que pueden ser, a la vez, sujetos y objetos de dicha acción. Frente a esta característica manifiesta de un "saber-hacer" demostrado, el quehacer praxeológico tendrá que ejercer una mirada crítica sobre el discurso, los métodos y los resultados; una mirada más incisiva, buscando las debilidades de la acción más allá del discurso de los practicantes de la misma, lo que permitirá juzgar su pertinencia para una nueva experimentación, en un contexto diferente.

\section{LAFASE DEL JUZGAR}

Esta es la fase de reacción (JUZGAR) que responde a la pregunta ¿̇qué puede hacerse?; etapa fundamentalmente hermenéutica en la que el educador/praxeólogo examina otras formas de enfocar la problemática de la práctica, visualiza y juzga diversas teorías, de modo que pueda comprender la práctica, conformar un punto de vista propio y desarrollar la empatía requerida para participar y comprometerse con ella. Es la fase paradigmática pues le corresponde formalizar, después de la observación, experimentación y evaluación (fase empírica o experimental), los paradigmas de la praxis, es decir, los modelos transferibles de acción que permitan que otros practicantes la puedan realizar. A título de ejemplo se pueden señalar algunos modelos de acción educativa que se han popularizado y transferido por todas partes: la repetición/memorización como medio de aprendizaje, las pedagogías activas de Freinet, las ciudadelas de los niños como experiencia de base de la ciudadanía y de la responsabilidad democrática, el análisis y el debate sobre las películas en los cine-foros, la expresión libre y la creación colectiva en los talleres de teatro, etcétera. En todo, caso ningún modelo de acción es universal ni permite responder a la multiplicidad y complejidad de las situaciones educativas; de ahí la necesidad de buscar experiencias y de enriquecer el potencial de los "saber-hacer".

¿Cómo se articula esta interpretación de la práctica educativa? Cuatro momentos $\mathrm{d}$ i m e n s i o n a e s te e i e hermenéutico/paradigmático: el primero consiste en problematizar la propia observación. Y ello porque cada uno tiene sus "lentes de sentido" que, conscientemente o no, condicionan su manera de ver, de comprender y de actuar. Problematizar aquí consiste en identificar los propios "lentes" puesto que los problemas que hemos detectado tienen relación con nuestra visión del mundo, del hombre, de la sociedad, de la educación, etcétera. El segundo momento conduce a la formulación de una hipótesis de sentido, lo que supone que estamos "dudando" 
de la realidad tal y como fue formulada y problematizada en el momento de la observación: sospechamos que otra cosa es posible. El tercer momento busca formular los discursos (pedagógico, filosófico, sociológico, entre otros) que confirmarán la situación tal como fue descrita luego de la problematización: en el fondo es justificar un modo de actuar. El cuarto momento invita a un retorno a las fuentes, retorno crítico, distante y riguroso. $Y$ no se trata de recurrir a la tradición para justificar el actuar deseado; por el contrario, la mayor parte de las veces, la elección de las fuentes y su análisis riguroso obligan a una reformulación de la propia problematización. El conjunto de este proceso conducirá a un intento de interpretación que llevará a percibir intuitivamente las acciones que hay que promover para reorientar o mejorar la práctica educativa.

\section{LAFASE DEL ACTUAR}

La tercera fase del proceso praxeológico es la fase del actuar que responde a la pregunta ¿̇Qué hacemos en concreto?, etapa fundamentalmente programática en la que el educador/praxeólogo construye, en el tiempo y el espacio de la práctica, la gestión finalizada y dirigida de los procedimientos y tácticas previamente validados por la experiencia y planteados como paradigmas operativos de la acción. En esta etapa la praxeología instruye y guía la praxis, el educador/praxeólogo se convierte en quien ilumina al practicante, sobre todo cuando él mismo es un practicante/educador; se pasa, entonces, de la investigación experimental a la aplicación práctica. Cuando se llega a este momento, se comprende que actuar no es únicamente la aplicación de políticas venidas de fuera. Un mejor conocimiento de sí mismo, del medio, de los diversos actores conduce a un rigor en la formulación, la planeación y la elaboración estratégica de la acción educativa, que se desea, al mismo tiempo, eficiente y eficaz. Es así que el educador/praxeólogo buscará precisar bien los objetivos, que le permitirán discernir mejor los núcleos de la acción, los medios y las estrategias. Además, se verá obligado a equiparse de una serie de herramientas que mejorarán su trabajo, por ejemplo, ciertas habilidades técnicas.
El descubrimiento de paradigmas de la praxis educativa es la función central del educador/praxeólogo; la experiencia y la experimentación, el análisis y la interpretación son requerimientos para ello, pero la aplicación pertinente es el objetivo. Aquí se formula la hipótesis de un paradigma general de la praxis educativa que tendría estos elementos:

- La comprensión de los procesos educativos, la identificación de las problemáticas y la determinación de las finalidades.

- Los campos de práctica y los modos de acción educativos.

- La construcción de proyectos, la gestión de las acciones y la evaluación de los mismos.

En otras palabras, se pretende la operacionalización de un proyecto de acción. Los objetivos generales son la eficiencia (rendimiento) y la eficacia (resultados) al servicio de una transformación real de la práctica. Se propone esta nueva intervención como ajuste y relanzamiento teniendo en cuenta el procedimiento que se ha seguido hasta ahora: después de observar la realidad de la práctica (la referencia a la experiencia) y plantear un diagnóstico comprensivo de la misma, desde una referencia a las disciplinas y una hermenéutica que permite aprehender la "función revelante" de las prácticas (la intención de cambio), se propone una nueva práctica de gestión participativa. Se trata de desencadenar un verdadero proceso de cambio, de transformación: ¿Cómo responder concretamente a las esperanzas, iniciar los desplazamientos, vivir lo novedoso?

\section{LAFASE DE LA DEVOLUCION CREATIVA}

Esta cuarta fase es la de la reflexión en la acción (DEVOLUCION CREATIVA), etapa fundamentalmente prospectiva que responde a la pregunta: ¿Qué aprendemos de lo que hacemos? La prospectiva es una representación que pretende orientar el proyecto y la práctica del 
educador/praxeólogo; una representación donde el futuro es planteado a priori como un ideal. Tiene una función de sueño, de deseo, de anticipación. Ella pretende un actuar y nuevas vías de acción, un cambio y no una simple descripción de lo que va a pasar; en otras palabras, ella comprende una dimensión evaluativa desde otro futuro. La prospectiva pretende, igualmente, desplegar las posibilidades de la intervención previsible a mediano y largo plazo; retornar al corazón de la práctica, a su memoria y su promesa, al horizonte de sentido y la presencia de lo Otro. Los actoressujetos están llamados a recentrarse sobre lo que los hace vivir y los impulsa a comprometerse en una praxis responsable. La prospectiva está orientada a la utopía del tipo de sociedad, de hombre y de mujer y de comunidad que la nueva intervención pretende realizar desde ya en su apertura al futuro. Esta utopía permanece anclada en lo real y pide una evaluación constante de las tareas a realizar en el tiempo y el espacio.

Es la etapa en la que el educador/praxeólogo recoge y reflexiona sobre los aprendizajes adquiridos a lo largo de todo el proceso, para conducirlo más allá de la experiencia al adquirir conciencia de la complejidad del actuar y de su proyección futura. Incluso si la prospectiva no aparece metodológicamente sino al final, ella ha atravesado todo el proceso praxeológico. Se trata de un acto existencial autogenerador de teoría a partir de la experiencia que requiere ser "sacado a la luz", a través de un proceso mayeútico que le permita objetivar dicha experiencia, formalizarla, entrando así en el orden del discurso (así se corra el riesgo de deformar la experiencia): es una recuperación de la praxis por el logos, (inter y autoestrurante). Se trata del dialogo establecido entre educandos y prácticas, que permite desarrollar mas los conocimientos de estos. La devolución creativa ${ }^{18}$ tiene la intención de que el praxeólogo exprese los significados más importantes de su proceso y los exprese creativamente.
Por último, hay que tener en cuenta que el procedimiento praxeológico se articula sobre cuatro polos o componentes adicionales:

- Una fenomenología amarrada a la experiencia: se trata de un razonamiento sobre una situación (la práctica) a describir, a comprender, a interpretar, previendo su evolución en función de las acciones que se provecta realizar y de los compromisos que ellas implican;

- Una teleología, precisada desde las intenciones: son los objetivos, es decir, lo que se pretende obtener, modificar, crear - cambiar en la práctica, integrando las oportunidades y las amenazas;

- Una operacionalidad en la acción: aquí entran las decisiones, es decir, las opciones realizadas entre las diversas hipótesis de acción, en función del nivel y de la jerarquía de apuestas posibles;

- Una axiología fundada en valores: la ética, o sea los valores filosóficos, morales o políticos en juego.

En síntesis, la praxeología no puede evitar una formalización (teoría) de saberes: al intentar comprender una práctica, está formalizando una acción que produce saberes, está precisando la experiencia acumulada por medio de acciones. $Y$ si se trata de acciones educativas, indudablemente está generando, a partir de ellas, teoría pedagógica.

Retomando la clásica analogía de Francis Bacon ${ }^{19}$, el praxeólogo no es ni un simple empirista que, como la hormiga, recoge los frutos de su búsqueda de alimento simplemente para usarlos, ni un simple lógico que, como la araña, fabrica su tela a partir de su propia sustancia;

18. Concepto con el cual Vygotski hace referencia a la interacción y aportes que hacen los educandos entre si. Ésta expresará lo que cada grupo quiera decir, desde el sentimiento y la emoción, con la más amplia libertad. Se observa, por ejemplo, en un grupo de estudio cuando entre ellos se contestan las dudas.

19. Bacon (Novum Organum Libro l, aforismo 95) usa su símil para diferenciar los empíricos que, como hormigas, simplemente acumulan información o datos, los dogmáticos que, como arañas, extraen de sí mismos todo el conocimiento y, finalmente, los inductivista-gradualistas que, como las abejas, recogen el néctar para elaborarlo en miel. Este auténtico quehacer de las abejas es lo que se plasmaría en el Novum organum, y por ende manifiesto metodológico del nuevo pensamiento filosófico-científico. 
sino, ante todo, una abeja que fabrica su miel a partir de las flores, la transforma y la digiere para obtener su propia energía.

\section{REFERENCIAS BIBLIOGRÁFICAS}

Alvarez Yagüez, J. (2000). Individuo, libertad y comunidad. Liberalismo y Republicanismo, dos modos de entender la ciudadanía. A Coruña: Ludus.

Arendt, H. (1993). La condición humana. Barcelona: Paidós.

Bacon, F. [1620] (2004). Novum Organum. (trad. Clemente Almori). Buenos Aires: Losada.

Becerril, S. (1999). Comprender la práctica docente. Categorías para una interpretación científica. México: Plaza y Valdés Editores.

Berger, P. Y Luckmann, T. (1986). La construction sociale de la réalité. Paris : Meridiens.

Bernabeu, J.L. (1997). "Educación y dimensiones de la educación". En: COLOM, A. (coord.). Teorías e instituciones contemporáneas de la educación. Barcelona: Ariel.

Bourdieu, P. (1972). Esquisse d'une théorie de la pratique. Paris : Droz.

Bourdieu, P. (2003). Capital cultural, escuela y espacio social. Buenos Aires: Siglo XXI.

Bourdieu, P. (2003a). El oficio de científico. Ciencia de la ciencia y reflexividad. Barcelona: Anagrama.

Bruner, J. [1971] (1987). La importancia de la educación. Barcelona: Paidós.

Cabello, M.J. (2002). Educación permanente y educación social. Málaga: Ed. Aliibe.

Delors, J. (coord.) (1996). La educación encierra un tesoro. Madrid: Santillana-UNESCO

Dewey, J. [1916] (2001). Democracia y educación. Madrid: Morata.

Durkheim, É. (1998). Educación y pedagogía. Ensayos y controversias. Buenos Aires: Losada.

Freire, P. (1990). La naturaleza política de la educación, Barcelona: Paidós.
Freire, P. (1998). Pedagogía de la autonomía. México: SigloXXI.

Fuentes, C. (1992). El espejo enterrado. México: FCE.

Fullat, O. (1983). Filosofías de la educación. Barcelona: Ceac.

García Carrasco, J (1984). Teoría de la educación. Madrid: Anaya.

García Molina, J. (2003). Dar (la) palabra. Deseo, don y ética en educación social. Barcelona: Gedisa.

Geremek, B. (1996.) Título en DELORS, J. (coord.). La educación encierra un tesoro. Madrid: SantillanaUNESCO

Giroux, H. (1990). Los profesores como intelectuales. Barcelona: Paidós.

Giroux, H. (1992). Teoría y resistencia en educación. México: SigloXXI.

González, J. M. (1996). "El individuo y la sociedad". En Cruz, M. (comp.). Tiempo de subjetividad. Barcelona: Paidós, págs. 19-38.

Groundy, S. (1991). Producto o praxis del currículum. Madrid: Morata.

Juliao, C. (2002). La praxeología: una teoría de la práctica. Bogotá: Uniminuto.

Magendzo, A. (2003). Formación ciudadana, un tema controvertido de la educación. Consultado el $24 \quad 0 \mathrm{ctubre} \quad 2006 \quad \mathrm{e} \mathrm{n}$ hHp://ww2.educarchile. $\mathrm{cl} / \mathrm{ntg} /$ investigador/1560/a rticle-76484.html

Martínez, A. (1990). "La enseñanza como posibilidad del pensamiento". En Pedagogía, discurso y poder. Bogotá: Coprodic.

Martínez Bonafé, J. (2001). Arqueología del concepto de compromiso social en el discurso pedagógico y de formación docente. México: Revista Electrónica de Investigación Educativa, $\mathrm{N}^{\circ} 3$. Consultado el 20 de octubre de 2006 en http://redie.ens.uabc. mx/vol3nol/contenidobonafe.html

Mejia, M. y Awad, M. (2003). Educación popular hoy. En tiempos de globalización. Bogotá: Aurora 
Meirieu, P. (1998). Frankenstein educador. Barcelona:

Alertes.

Quintana, J.M. (1991). Pedagogía comunitaria. Madrid: Narcea.

Rodríguez, C. (2003). "La renovación del pensamiento crítico en América Latina: el aporte de Santos", introducción al libro de SANTOS, Boaventura. La caída del Angelus Novas: ensayos para una nueva teoría social y una nueva práctica política. Bogotá: ILSA-Universidad Nacional de Colombia.

Savater, F. (1997). El valor de educar. Barcelona: Ariel.

Schön, D. (1998). El profesional reflexivo: cómo piensan los profesionales cuando actúan. Barcelona: Paidós.

St-arnaud, Y. L'hotellier, A. (1992). Connaître par I'action. Montreal: Presses de l'Universite de Montreal. 